\title{
Erratum to: Controlled Tissue Expansion in the Initial Management of the Short Bowel State
}

\author{
F. Murphy $\cdot$ B. A. Khalil $\cdot$ S. Gozzini $\cdot$ \\ B. King $\cdot$ A. Bianchi $\cdot$ A. Morabito
}

Published online: 21 December 2011

(C) Société Internationale de Chirurgie 2011

\section{Erratum to: World J Surg (2011) 35:1142-1145 \\ DOI 10.1007/s00268-011-0991-0}

The authors have brought to our attention the need for revision to Table 1 in their original article. While the overall conclusion of the article did not change, the correct bowel length values are represented in the table below.
The online version of the original article can be found under doi:10.1007/s00268-011-0991-0.

F. Murphy $(\bowtie) \cdot$ B. A. Khalil · S. Gozzini · B. King ·

A. Bianchi - A. Morabito

Department of Paediatric Surgery, Royal Manchester Children's

Hospital, Oxford Road, Manchester M13 9WL, UK

e-mail: Fiona.murphy@doctors.org.uk
Table 1 Patient diagnosis and pre and post bowel expansion lengths

\begin{tabular}{llll}
\hline Patient & Diagnosis & $\begin{array}{l}\text { Pre expansion } \\
\text { length }(\mathrm{cm})\end{array}$ & $\begin{array}{l}\text { Post expansion } \\
\text { length }(\mathrm{cm})\end{array}$ \\
\hline 1 & Jejunal atresia & 25 & 43 \\
2 & Gastroschisis & 45 & 60 \\
3 & Gastroschisis & 67 & 85 \\
4 & Vanishing & 30 & 45 \\
& Gastroschisis & & \\
5 & Gastroschisis & 25 & 25 \\
6 & Gastroschisis & 25 & 25 \\
7 & Gastroschisis & 34 & 34 \\
8 & Gastroschisis & 10 & 10 \\
9 & Necrotising & 5 & 8 \\
& enterocolitis & & 35 \\
10 & Necrotising & 30 & 37 \\
& enterocolitis & & \\
Mean & & 29.6 &
\end{tabular}

Overall percentage increase in bowel length: $20 \%$. Range of actual length of increase: $0-18 \mathrm{~cm}$ 